\title{
The study of antifriction aluminum alloys containing iron, before and after tribological tests
}

\author{
O. O. Shcherbakova ${ }^{1, \dagger}$, T. I. Muravyeva ${ }^{1}$, D. I. Zagorskiy ${ }^{1,2}$ \\ †'shcherbakovaoo@mail.ru
}

${ }^{1}$ Ishlinsky Institute for Problems in Mechanics of RAS, 101/1 Vernadskogo ave., Moscow, 119526, Russia

${ }^{2}$ Gubkin Russian State University of Oil and Gas, 65/1 Leninsky ave., Moscow, 119991, Russia

\begin{abstract}
Experimental aluminum alloys with the addition of iron, which model the materials obtained with the addition of recyclables, were investigated. The use of the recyclable (silumin waste, production waste, remelting of canned scrap, etc.) seems to be promising for the national economy. In the work, the alloy of the $\mathrm{Al}-6 \% \mathrm{Sn}-5 \% \mathrm{Si}-4 \% \mathrm{Cu}$ (mass. \%) system was used as a base, to which iron (1\%) and other elements (bismuth, lead, manganese) were added. The samples under investigation were subjected to heating up to $500^{\circ} \mathrm{C}$ and cooling in various regimes. It was shown that the best results were achieved with cooling in water: the phases were spheroidized and properties were improved. Complex method of microscopy, including optical, electronic (with X-ray spectral microanalysis), and probe microscopy was used, in order to study alloys before and after tribological tests. An investigation of the initial structure of the samples showed that the combined addition of iron with manganese $(0.5 \%)$ led to the formation of favorable skeletal phases. The tribological tests without lubrication which modeled the extreme conditions of operation were carried out. These experiments showed that the investigated alloy had an increased wear resistance, which could be associated with the formation of skeletal phases. After tribological tests, significant changes in the structure and phase components at the surface and in the near-surface layer were observed. For the study of this layer, an oblique cut was made, on which near-surface area with a thickness of $50-100 \mu \mathrm{m}$ was detected.
\end{abstract}

Keywords: aluminum alloys, antifriction materials, tribological test, spectral analysis, microscopy, phase composition, microstructure.

УДК: 669.2

\section{Исследование антифрикционных алюминиевых сплавов, содержащих железо, до и после трибологических испытаний}

\author{
Щербакова О. О ${ }^{1, \dagger}$, Муравьева Т. И. ${ }^{1}$, Загорский ${ }^{1,2}$
}

${ }^{1}$ Институт проблем механики им. А. Ю. Ишлинского РАН, просп. Вернадского, 101/1, Москва, 119526, Россия ${ }^{2}$ РГУ Нефти и Газа им. И. М. Губкина, Ленинский просп., 65/1, Москва, 119991, Россия

Проведены исследования экспериментальных алюминиевых сплавов (ЭАС) с железом, моделирующих материалы, полученные с добавлением вторсырья. Использование последнего (отходов собственного производства, переплава баночного лома и пр.) представляется весьма перспективным направлением в народном хозяйстве. В работе, в качестве базового, использовали сплав системы $\mathrm{Al}-6 \% \mathrm{Sn}-5 \% \mathrm{Si}-4 \% \mathrm{Cu}$ (масс. \%), в который добавляли железо (около 1\%) и некоторые другие элементы (висмут, свинец и марганец). Исследуемые образцы подвергали нагреву до $500^{\circ} \mathrm{C}$ с последующим охлаждением в различных режимах. Показано, что при охлаждении в воде достигаются наилучшие результаты: происходит сфероидизация фаз (легкоплавкой ( $\mathrm{Sn}-\mathrm{Pb}-\mathrm{Bi})$ и кремниевой (Al-Si)), которая приводит к улучшению механических и трибологических свойств. Для изучения сплавов до и после испытаний в работе применяли комплексную методику исследования поверхности образцов, включающую оптическую, электронную (с рентгеноспектральным микроанализом) и зондовую микроскопии. Исследование исходной структуры образцов установило, что совместное введение железа с марганцем (0,5\%) в состав сплава, приводит к образованию благоприятных фаз скелетообразной формы. Проведены трибологические испытания без смазки, которые моделировали экстремальные условия эксплуатации узла трения. Эти испытания показали, что исследуемый алюминиевый железосодержащий сплав имеет повышенную износостойкость, которая может быть связана с образованием скелетообразных фаз. После трибологических испытаний обнаружены значительные изменения структуры и фазовых составляющих, как на поверхности, так и в приповерхностном слое. Для детального изучения последнего приготавливался косой срез, на котором обнаружена приповерхностная область, толщина которой составляет 50 - 100 мкм.

Ключевые слова: алюминиевые сплавы, антифрикционные материалы, трибологические испытания, рентгеноспектральный анализ, микроскопия, фазовый состав, микроструктура. 


\section{1. Введение}

Для большинства конструкций в машиностроении большое значение имеют материалы, используемые в трущихся деталях, в частности в подшипниках скольжения [1 -3]. Срок их службы зависит, от правильного, научно обоснованного выбора состава сплавов. В настоящее время для изготовления подшипников чаще всего применяются дорогостоящие сплавы, в основном на основе меди (бронзы), поэтому актуальной задачей является создание более дешевых и надежных материалов $[4,5]$. Сплавы на основе алюминия отвечают таким требованиям, обладая при этом сопоставимыми с бронзами антифрикционными характеристиками [6-11].

Известно, что антифрикционные материалы должны обладать эффектом самосмазывания, который заключается в выделении мягкой фазовой составляющей на трущиеся поверхности. Образовавшаяся защитная пленка вторичных структур (ВС) в критических условиях трения выполняет роль твёрдой смазки, предотвращающей разрушение поверхности вала [12]. Поэтому важным аспектом является детальное изучение процессов, происходящих при контактном взаимодействии в процессе трения. В связи с этим целесообразно проводить оценку изменений материала, как на поверхности контакта, так и в приповерхностной области, так как изменение поверхности непосредственно связано с изменением различных приповерхностных слоев.

В работах $[13,14]$, построены фазовые диаграммы, на основе которых подобраны составы многокомпонентных антифрикционных алюминиевых сплавов. Дальнейшие экспериментальные исследования позволили выбрать оптимальные базовые составы на основе системы Al-Si-Cu-Sn. Изучаемые в этих работах сплавы были изготовлены из чистого (первичного) алюминия. Вместе с тем, представляет интерес получения сплавов на основе различных типов вторичного сырья. Такие материалы являются более дешевыми и доступными, поэтому их использование дало бы несомненный экономический эффект. Для моделирования этих материалов в данной работе в базовые алюминиевые сплавы добавлялось железо, поскольку его появление является неизбежным следствием в составе конечного продукта. Однако известно: введение железа в алюминиевые сплавы обычно приводит к образованию фаз игольчатой формы, которые неблагоприятно сказывается на их механических свойствах. В то же время, добавление марганца приводит к образованию фаз скелетообразной формы, компенсирующих вредное влияние железа. Целесообразность дополнительного введения марганца в состав исследуемых сплавов также была оценена в настоящей работе.

Цель работы: Оценить влияние структуры и элементного состава железосодержащего алюминиевого сплава на трибологические свойства и изменения поверхностных и приповерхностных слоев, происходящие в процессе трения.

\section{2. Материалы и методы исследования}

\section{1. Приготовление и подготовка образиов}

Объектом исследования является экспериментальный антифрикционный алюминиевый сплав (ЭАС). Сплав изготовили на основе базовой композиции $\mathrm{Al}-6 \% \mathrm{Sn}-5 \% \mathrm{Si}-4 \% \mathrm{Cu}$ (масс. \%) с добавлением железа (около $1 \% \mathrm{Fe}$ ) и других элементов. В настоящей работе ЭАС сравнивали со сплавом базовой композиции. Контроль химического состава проводили на спектрометре ARL 4460 OES (фирма THERMO FISHER). Фактический состав ЭАС представлен в Табл. 1.

Табл. 1. Химический состав экспериментального сплава ЭАС. Table 1. Chemical composition of the experimental alloy EAA.

\begin{tabular}{|c|c|c|c|c|c|c|c|c|c|c|}
\hline \multicolumn{10}{|c|}{ Концентрация, масс.\% } \\
Concentration, mass. \% \\
\hline $\mathrm{Si}$ & $\mathrm{Cu}$ & $\mathrm{Sn}$ & $\mathrm{Pb}$ & $\mathrm{Bi}$ & $\mathrm{Al}$ & $\mathrm{Fe}$ & $\mathrm{Zn}$ & $\mathrm{Mg}$ & $\mathrm{Mn}$ & $\mathrm{Ni}$ \\
\hline 5.1 & 4.3 & 5.6 & 0.4 & 0.4 & 82.8 & 0.7 & 0.1 & $<0.01$ & 0.5 & 0.03 \\
\hline
\end{tabular}

После отливки, слитки подвергали термообработке (использовали муфельную электропечь SNOL 8,2/1100). При этом слитки нагревали до температуры $500^{\circ} \mathrm{C}$ и выдерживали при этой температуре до 6 ч. После выдержки применяли охлаждение с разной скоростью - закалка в воде, охлаждение на воздухе и охлаждение с печью. Для изучения структуры и фазового состава сплавов изготовили шлифы литых и термообработанных отливок. Для исследования изменений в приповерхностном слое после трибологических испытаний проводили изучение косых срезов (под углом $45^{\circ}$ ) образца. Экспериментальный сплав изучали до и после испытаний.

\section{2. Испьтания}

Трибологические испытания проводили на трибометре Т-05, моделирующем работу узла трения по схеме «колодка-ролик» (материал ролика - Сталь 45), с пошаговым изменением давления до 2 МПа [15]. Испытывали образцы в условиях без смазки с целью изучения поведения сплава при возможных экстремальных режимах эксплуатации (пуск-остановка, ударные нагрузки).

\section{3. Микроскопия}

В данной работе применяли комплексную методику микроскопических исследований. На начальном этапе использовали оптический микроскоп (OM) «Neophot-2». Основные микроскопические исследования проводили на сканирующем электронном микроскопе (СЭМ) "FEI «Quanta-650» (ускоряющее напряжение до 30 кВ) с детектором вторичных электронов и энергодисперсионным микроанализатором EDAX. Исследование поверхности с нанометровым разрешением проводили на сканирующемзондовоммикроскопе $(\mathrm{C} 3 \mathrm{M})$ «SmartSPM ${ }^{\mathrm{TM}}$ ». Использовали режим тейпинга (резонансная частота 250 кГц), применяли кантилевер fpN10 c радиусом кривизны ост- 
рия 20 нм. Особенностью данного микроскопа является наличие встроенной оптической камеры для предварительного выбора участка поверхности.

\section{3. Исследование исходной структуры поверхности ЭАС}

\section{1. Оптическая микроскопия}

Предварительное сравнение структур базового и железосодержащего (ЭАС) сплавов до и после термообработки на макроуровне показало, что происходит значительное изменение структуры поверхности. После термообработки удлинённые фазовые составляющие сплава приобрели более компактную округлую форму. Можно отметить, что добавление железа приводит к появлению включений скелетообразной формы. Вместе с тем, оптическая микроскопия не позволяет детально изучить особенности поверхности, поэтому при дальнейших исследованиях была применена электронная микроскопия. Предварительное использование метода оптической микроскопии даёт возможность выбора участка поверхности для последующих исследований.

\section{2. Электронная микроскопия}

На данном этапе изучалось влияние термообработки на структуру поверхности сплавов. Исследуемые образцы подвергали трем режимам охлаждения: с печью, на воздухе и в воде. На Рис. 1 показаны микроструктура поверхности базового сплава и ЭАС в литом состоянии и после термообработки с охлаждением в воде.

Исследования показали, что наибольшее изменение структуры сплавов происходит после закалки в воде: в этом случае частицы кремния стремятся максимально сфероидизироваться. Частицы олова, также приобретают глобулярную форму, и происходит уменьшение концентрации меди на поверхности (последнее связано со значительным растворением меди в алюминиевой матрице). Отличительной особенностью ЭАС является по- явление фаз скелетообразной формы, состоящих из алюминия, железа, марганца и кремния $-\mathrm{Al}_{15}(\mathrm{Fe}, \mathrm{Mn})_{3} \mathrm{Si}_{2}$ (Рис. 1c, d).

Установлено, что при охлаждении на воздухе и с печью изменения носят тот же характер, что и при охлаждении в воде, однако выражены в меньшей степени. Таким образом, как и для других случаев, термообработка с закалкой в воде является оптимальным режимом обработки. Перечисленные изменения характерны и для базового сплава.

Для более детальной идентификации фаз получены карты распределения отдельных химических элементов на поверхности ЭАС после термической обработки с охлаждением в воде (Рис. 2).

Как видно из рисунка, в структуре сплава четко выявляются частицы Si (Рис. 2d), которые трудно различимы на изображении микроструктуры, полученном на сканирующем электронном микроскопе (Рис. 1d). Отметим малое количество меди, очевидно входящей в состав фазы $\mathrm{Al}_{2} \mathrm{Cu}$ (Рис. 2c). Мягкая фаза, состоящая из 6\% олова (Рис. 2b), 0,4\% висмута и $0,4 \%$ свинца, после отжига приобрела глобулярную форму (на Рис. 2 карты распределения $\mathrm{Bi}$ и $\mathrm{Pb}$ не приведены, т. к. их массовая доля мала и, в отличие от $\mathrm{Mn}$, они не образуют химических соединений с другими элементами сплава).

Железо и марганец на карте наблюдаются в одном месте (Рис. 2е,f). Проведённый рентгеноспектральный анализ показал: в сплаве ЭАС четко выявляется фаза, содержащая Al-Si-Fe-Mn, скелетообразной формы, как в литом, так и в термообработанном состоянии. Из литературы $[16,17]$ известно, что в некоторых алюминиевых сплавах, содержащих железо, например, в силуминах, обычно образуется хрупкое соединение $\mathrm{Al}_{5} \mathrm{FeSi}$, кристаллизующееся в виде тонких пластин (игл). Данные включения введут к резкому снижению механических свойств, особенно к уменьшению пластичности. Для нейтрализации вредного влияния железа в сплавы вводят марганец $(0,2-0,6 \%)$, за счет чего в сплавах формируется соединение $\mathrm{Al}_{15}(\mathrm{Fe}, \mathrm{Mn})_{3} \mathrm{Si}_{2}$, которое кристаллизуется в виде компактных ограненных кристаллов

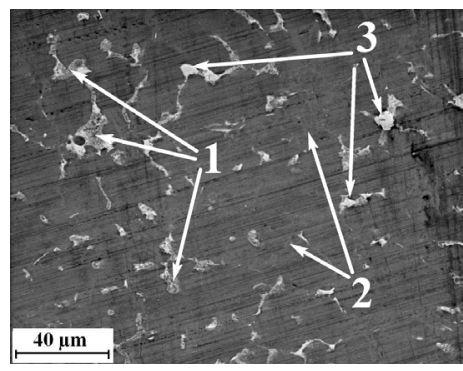

a

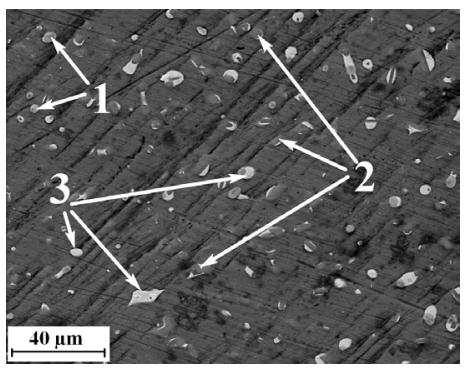

b

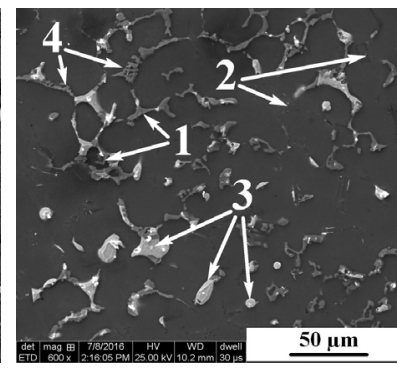

$\mathrm{C}$

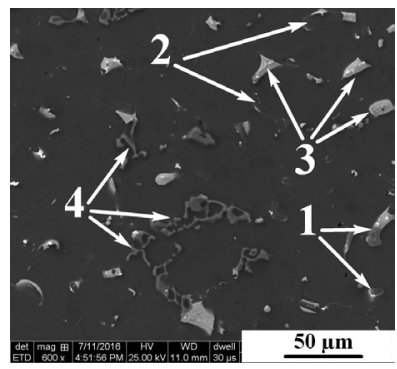

d

Рис. 1. Микроструктура поверхности: базового сплава $\mathrm{Al}-\mathrm{Si}-\mathrm{Cu}-\mathrm{Sn}$ в литом состоянии (а); базового сплава $\mathrm{Al}-\mathrm{Si}-\mathrm{Cu}-\mathrm{Sn}$ после термообработки с охлаждением в воде (b); сплава ЭАС в литом состоянии (c); сплава ЭАС после термообработки с охлаждением в воде (d). Фазы: $1-\mathrm{Al}_{2} \mathrm{Cu} ; 2-\mathrm{Al}-\mathrm{Si} ; 3-\mathrm{Sn} ; 4-\mathrm{Al}_{15}(\mathrm{Fe}, \mathrm{Mn})_{3} \mathrm{Si}_{2}(\mathrm{a}-\mathrm{d}-$ электронная микроскопия).

Fig. 1. Microstructure of the surface: base alloy Al-Si-Cu-Sn in the cast state (a); base alloy Al-Si-Cu-Sn after the heat treatment with cooling into the water (b); alloy EAA in the cast state (c); alloy EAA after the heat treatment with cooling into the water (d). Constituent: $1-\mathrm{Al}_{2} \mathrm{Cu}$; 2 - Al-Si; 3 - Sn; $4-\mathrm{Al}_{15}(\mathrm{Fe}, \mathrm{Mn})_{3} \mathrm{Si}_{2}(\mathrm{a}-\mathrm{d}-$ electronic microscopy). 


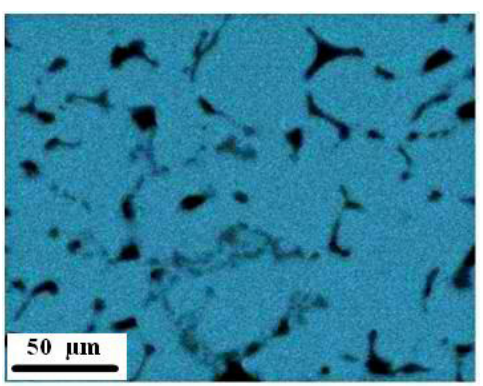

a

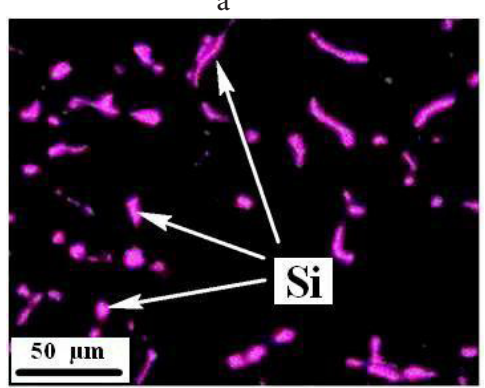

d

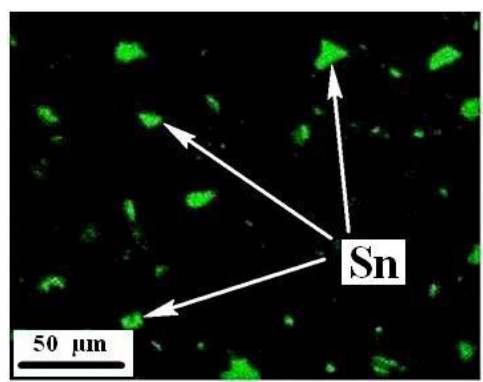

$\mathrm{b}$

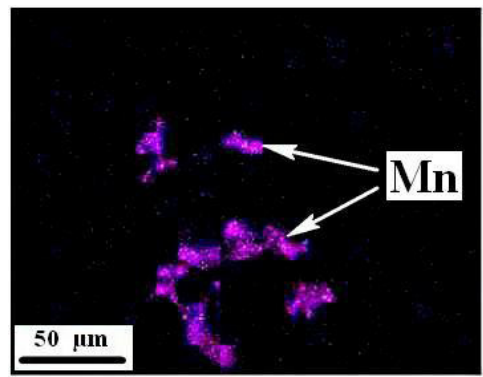

e

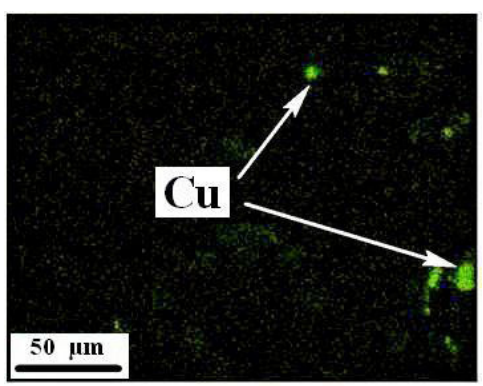

C

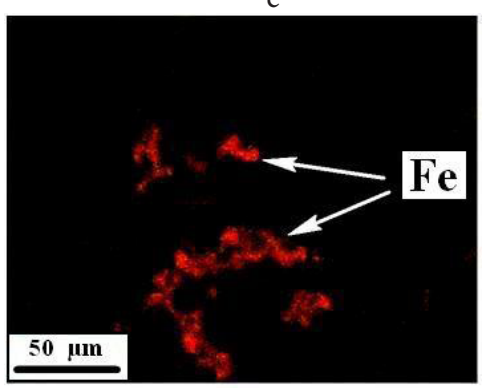

f

Рис. 2. Карта распределения отдельных элементов на поверхности ЭАС: $\mathrm{Al}$ (a); $\mathrm{Sn}$ (b); Cu (c); $\mathrm{Si}$ (d); $\mathrm{Mn}$ (e); Fe (f).

Fig. 2. Map of the distribution of individual elements at the EAS surface: $\mathrm{Al}$ (a); $\mathrm{Sn}$ (b); Cu (c); Si (d); $\mathrm{Mn}$ (e); Fe (f).

скелетообразной формы. Полученные кристаллы меньше охрупчивают сплавы, в отличие от вышеупомянутых тонких пластин (игл) [17]. Очевидно, что и в нашем случае марганец, добавленный в сплав ЭАС, полностью связал железо в фазу $\mathrm{Al}_{15}(\mathrm{Fe}, \mathrm{Mn})_{3} \mathrm{Si}_{2}$.

\section{3. Зондовая микроскопия}

Результаты, полученные в предыдущих разделах, значительно дополнены исследованиями с применением метода зондовой микроскопии. Отметим, что при исследованиях на электронном и зондовом микроскопах изучали один и тот же участок поверхности. Это достигнуто с помощью использования, ранее предложенного, метода - метки-репера, при изучении поверхности [18]. На Рис. 3, в качестве примера, представлены результаты, полученные для литого ЭАС: приведена микроструктура поверхности, полученная на электронном микроскопе с областям проведения элементного анализа, и зондовом микроскопе с соответствующим 3D-изображением.

Изображения микроструктуры поверхности образца ЭАС, полученные на электронном (СЭМ) и зондовом (С3М) микроскопах, хорошо коррелируют и существенно дополняют друг друга. На СЭМ изображении поверхности сплава кремний практически не виден на алюминиевой матрице и его трудно идентифицировать [16]. В то же время, на СЗМ картине эти элементы различаются очень хорошо. Кроме того, по СЗМ изображению удаётся построить профили по секущим и оценить параметры рельефа неровностей на поверхности. Скелетообразные фазы, состоящие из алюминия, железа, магния и кремния, чётко видны на обоих изображениях. В то же время, сравнение результатов показало, что фаза $\mathrm{Al}_{2} \mathrm{Cu}$ практически не видна на поверхности термообработанного образца (ни на изображениях, полученных на СЭМ, ни на СЗМ), это связано с её растворением во время термообработки. Таким образом, совместное использование сканирующей электронной и зондовой микроскопии позволяет визуализировать элементы, которые (из-за близости атомных номеров) трудноразличимы на изображениях, полученных на СЭМ. Это позволяет определить наличие и элементный состав отдельных фаз, а также оценить их пространственную геометрию.

\section{4. Исследование сплава ЭАС после трибологических испытаний}

Трибологические испытания в условиях трения без смазки позволили получить аналитические выражения для зависимости интенсивности изнашивания от давления в виде $I=f(P)[15,19]$ (где $P$ - давление):

- для базового сплава: $I=8.9 \cdot 10^{-8} P^{0,8}$,

- для сплава ЭАС: $I=8.2 \cdot 10^{-8} P^{0,7}$.

Полученные выражения зависимости достаточно близки. Вместе с тем, для ЭАС множитель, как и показатель степени давления несколько меньше, чем для базового сплава. Это говорит о том, что интенсивность изнашивания у ЭАС меньше. Таким образом, полученные результаты позволяют сделать вывод: сплав ЭАС имеет лучшие трибологические характеристики.

Пример результатов микроскопических исследований поверхности сплава ЭАС после трибологических тестов приведен на Рис. 4a.

Фотография микроструктуры поверхности (Рис. 4a) демонстрирует сильное изменение рельефа - видны продольные полосы, определяемые направлением трения. Проведённый элементный анализ позволил установить, что состав поверхности на различных участках примерно одинаков. Сравнение полученных данных с исходными показало: состав поверхности после испытаний в целом изменился незначительно. Однако следует 


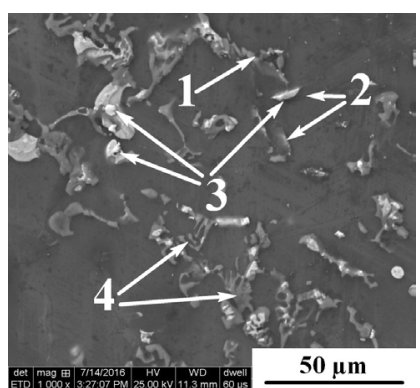

a

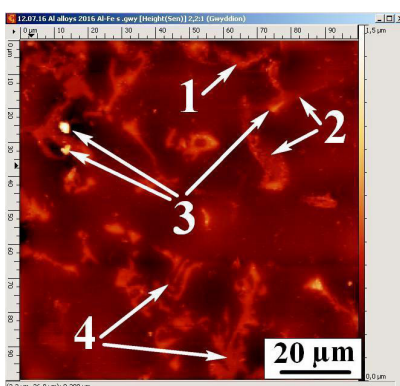

$\mathrm{b}$

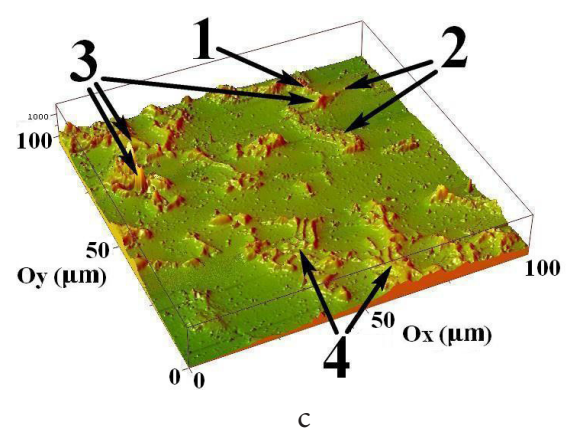

Рис. 3. Микроструктура поверхности литого образца ЭАС, изображения получены на электронном микроскопе (а); на зондовом микроскопе: 2D (b) и 3D (c). Фазы: $1-\mathrm{Al}_{2} \mathrm{Cu} ; 2-\mathrm{Al}-\mathrm{Si} ; 3-\mathrm{Sn} ; 4-\mathrm{Al}_{15}(\mathrm{Fe}, \mathrm{Mn})_{3} \mathrm{Si}_{2}$.

Fig. 3. Microstructure of the surface of the cast EAS sample, the images were obtained on an electron microscope (a); on a probe microscope: $2 \mathrm{D}(\mathrm{b})$ and $3 \mathrm{D}(\mathrm{c})$. Constituent: $1-\mathrm{Al}_{2} \mathrm{Cu} ; 2-\mathrm{Al}-\mathrm{Si} ; 3-\mathrm{Sn} ; 4-\mathrm{Al}_{15}(\mathrm{Fe}, \mathrm{Mn})_{3} \mathrm{Si}_{2}$.

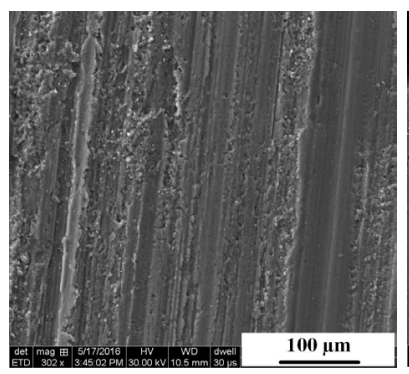

a

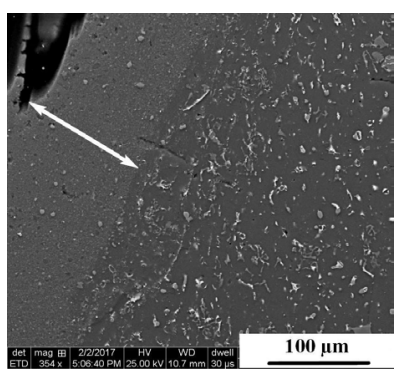

$\mathrm{b}$

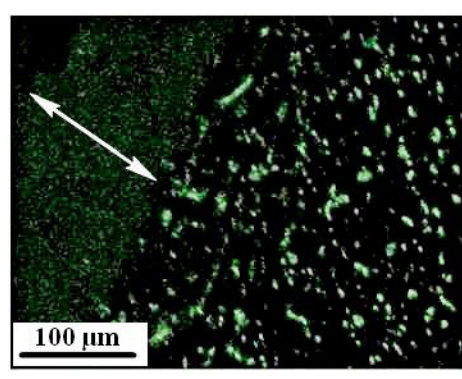

C

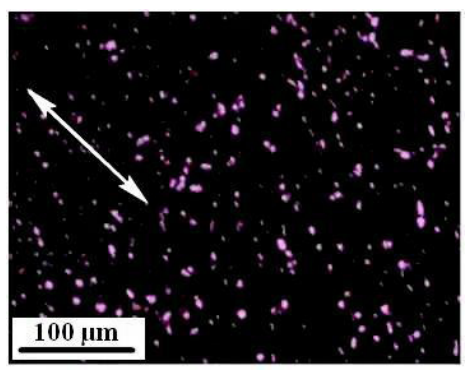

$\mathrm{d}$

Рис. 4. Микроструктура образца ЭАС после трибологических испытаний при давлении 2 МПа: поверхность образца (а); косой срез образца (приповерхностный слой) (b); карта распределения Sn (c); карта распределения Si (d) (электронная микроскопия).

Fig. 4. Microstructure of the sample EAA after tribological tests at the pressure $2 \mathrm{MPa}$ : surface of the sample (a); oblique cut of the sample (near-surface layer) (b); map of the distribution of Sn (c); map of the distribution of Si (d) (electronic microscopy).

отметить появление кислорода - около $12 \%$, очевидно связанное с окислительными процессами, происходящими на поверхности в процессе трения.

Для более детального исследования изменений, происходящих при трении, был приготовлен косой срез колодки из сплава ЭАС. Это позволило изучить не только изношенный поверхностный слой, но и приповерхностные слои образца (указан стрелками на Рис. 4b,c,d). Анализируя косой срез, можно сравнить изменённый приповерхностный слой с материалом в объёме. Полученные результаты позволяют оценить толщину этого слоя (50-100 мкм) и свидетельствуют о значительном изменении характера распределения элементов в нём. Так, крупные включения фаз - легкоплавких элементов (Рис. 4c), а также железосодержащих (включающих марганец), не наблюдаются в приповерхностном слое. Поскольку элементный состав изменился незначительно (по сравнению с объёмом и поверхностью исходного образца), можно сделать вывод не об исчезновении, а о гомогенном перераспределении этих элементов. В то же время, тугоплавкие фазы (эвтектическое соединение $\mathrm{Al}-\mathrm{Si}$ и $\mathrm{Al}_{2} \mathrm{Cu}$ ) остаются в приповерхностном слое и не меняют своей конфигурации.

В ряде публикаций показано, что приповерхностный слой во время трибологических испытаний обедняется мягкой фазовой составляющей - оловом [12] в результате его выдавливания на поверхность при деформации материала в процессе трения. Это утверждение справед- ливо при работе контактной пары в нормальных условиях (например, в условиях граничной или полной смазки). В настоящей работе также обнаружено изменение приповерхностного слоя, однако, как уже было сказано, изменения носят несколько иной характер. Из-за сильного повышения температуры в контактной зоне при экстремальных условиях, эффект выдавливания не удается проследить - олово плавится уже в приповерхностном слое и перемешивается с алюминием и другими легкоплавкими элементами.

\section{5. Выводы}

Показано, что термообработка, независимо от режима охлаждения, приводит к сфероидизации легкоплавкой $(\mathrm{Sn}-\mathrm{Pb}-\mathrm{Bi})$ и кремниевой $(\mathrm{Al}-\mathrm{Si})$ фаз. Наибольшая эффективность термообработки достигается в случае быстрого охлаждения (закалка в воде).

Установлено, что толщина приповерхностного слоя образца из исследуемого сплава после трибологических испытаний без смазки составляет 50-100 мкм. Вследствие значительного повышения температуры в зоне контакта при экстремальных условиях трения, мягкая фазовая составляющая гомогенно перераспределяется в этом слое.

Показано, что добавление в экспериментальный алюминиевый сплав железа приводит к заметному изменению его структуры. Влияние небольших концентраций 
железа можно нейтрализовать введением марганца, который способствует образованию фазы благоприятной скелетообразной формы $\mathrm{Al}_{15}(\mathrm{Fe}, \mathrm{Mn})_{3} \mathrm{Si}_{2}$, наличием которой, возможно, объясняется увеличение твёрдости, приводящее к повышению износостойкости сплава. В целом результаты данной работы показывают возможность и перспективность использования вторичных материалов (содержащих железо) для изготовления антифрикционных алюминиевых сплавов.

Благодарность/Acknowledgements. Работа выполнена при поддержке Гранта РНФ 14-19-01033-П (микроскопические исследования) и по теме государственного задания № госрегистрации АААA-А17-117021310379-5 (приготовтение образиов и трибологические испьтания). Авторь выражают благодарность Н. А. Белову за предоставленные сплавы, Б.Я. Сачеку и А.М. Мезрину за проведение трибологических испьтаний./The work was supported by the Russian Scientific Foundation, project no. 14-19-01033-P (microscopic research) and on the state project registration no. AAAA-A17-117021310379-5 (sample preparation and tribological tests). The authors are grateful to N. A. Belov for the alloys provided, B. Ya. Sachek and A. M. Mezrin for performing of tribological tests.

\section{Литература/References}

1. B.N. Arzamasov, T.V. Soloveva, S.A. Gerasimov i dr. Spravochnik po konstrukcyonnym materialam: Spravochnik. Moscow, MGTU (2005) 640 p. (in Russian) [Б.Н. Арзамасов, Т.В. Соловьёва, С.А. Герасимов и др. Справочник по конструкционным материалам: Справочник. Москва, МГТУ (2005) 640 с.]

2. B. S. Ünlü, E. Atik. Materials and Design. 30, 1381 (2009). DOI: 10.1016/j.matdes.2008.06.069

3. D.E. Sander, H. Allmaier, H.H. Priebsch, F.M. Reich, M. Witt, T. Füllenbach, A. Skiadas, L. Brouwer, H. Schwarze. Tribology International. 81, 29 (2015). DOI: 10.1016/j.triboint.2014.07.021

4. A.E. Mironov, I.S. Gershman, A.V. Ovechkin, E.I. Gershman. Journal of friction and wear. 1(37), 31 (2016). (in Russian) [А.Е. Миронов, И.С. Гершман, А.В. Овечкин, Е.И. Гершман. Трение и износ. 1(37), 31 (2016).] DOI: 10.3103/S1068366616010128

5. A.E. Mironov, I.S. Gershman, A.V. Ovechkin, E.I. Gershman. Journal of friction and wear. 3(36), 334 (2015). (in Russian) [А.Е. Миронов, И.С. Гершман, А.В. Овечкин, Е.И. Гершман. Трение и износ. 3(36), 334 (2015).] DOI: 10.3103/S1068366615030095

6. Patent RF №2571665. (in Russian) [Патент РФ № 2571665.]

7. A.E. Mironov, I.S. Gershman, E.I. Gershman, M. M. Zheleznov. Journal of friction and wear. 2(38), 67 (2017). (in Russian) [А.Е. Миронов, И.С. Гершман, Е. И. Гершман, М. М. Железнов. Трение и износ. 2(38),
67 (2017).] DOI: 10.3103/S1068366617020155

8. E. Feyzullahoğlu, N. Şakiroğlu. Materials and Design. 31, 2532 (2010). DOI: 10.1016/j.matdes.2009.11.037

9. D.E. Lozanoa, R.D. Mercado-Solisa, A. J. Pereza, J. Talamantesb, F. Morales, M.A.L. HernandezRodriguez. Wear. 267, 545 (2009). DOI: 10.1016/j.wear.2008.12.112

10. R. A. Al-Samarai, K.R.A. Haftirman, Y. AlDouri. Procedia Engineering. 53, $616 \quad$ (2013). DOI: 10.1016/j.proeng.2013.02.079

11. X. Wanga, M. Nie, C.T. Wang, S.C. Wang, N.Gao. Materials \& Design. 83, 193 (2015). DOI: $10.1016 /$ j.matdes.2015.06.018

12. N. A. Bushe, I. G. Goryacheva, R. A. Korneev. Izvestiya VUZov. Severo-Kavkazskiy region. Tekhnicheskie nauki. Specvypusk, 35 (2001). (in Russian) [H. А. Буше, И. Г. Горячева, Р. А. Корнеев. Известия ВУЗов. СевероКавказский регион. Технические науки. Спецвыпуск, 35 (2001).]

13. N.A. Belov, A.O. Mikhailina, A.N. Alabin, O. O. Stolyarova. Metal Science and Heat Treatment. 3(58), 195 (2016). (in Russian) [Н. А. Белов, А. О. Михайлина, А. Н. Алабин, О. О. Столярова. МиТОМ. 4, 11 (2016).] DOI: $10.1007 /$ s11041-016-9988-5

14. N. A.Belov, O. O.Stolyarova, T. I.Muraveva, D. L.Zagorskiy. The Physics of Metals and Metallography. 6(117), 579 (2016). (in Russian) [Н.А. Белов, О.О. Столярова, Т.И. Муравьева, Д. Л. Загорский. ФММ. 6(117), 600 (2016).] DOI: 10.1134/S0031918X16040025

15. B. Y.Sachek, A. M.Mezrin, T. I.Muravyeva,O. O.Stolyarova, D.L. Zagorskiy, N.A. Belov. Journal of Friction and Wear. 2(36), 103 (2015). (in Russian) [Б.Я. Сачек, А.М. Мезрин, Т.И. Муравьёва, О.О. Столярова, Д.Л. Загорский, Н.А. Белов. Трение и износ. 2(36), 137 (2015).] DOI: 10.3103/S1068366615020142

16. V.S. Zolotorevskiy, N.A. Belov. Metallovedenie liteinyh aluminievyh splavov. Moscow, MISiS (2005) 375 p. (in Russian) [В.С. Золоторевский, Н.А. Белов. Металловедение литейных алюминиевых сплавов. Москва, МИСиС (2005) 375 с.]

17. I. I. Novikov, V. S. Zolotorevskiy, K. K. Portnoy, N. A. Belov i dr. Metallovedenie: Uchebnik. Moscow, MISiS (2009) 528 p. (in Russian) [И. И. Новиков, В. С. Золоторевский, К.К. Портной, Н.А. Белов и др. Металловедение: Учебник. Москва, МИСиС (2009) 528 с.]

18. O. O. Stolyarova, T.I. Muravyeva, D.L. Zagorskiy, N.A. Belov. Physical mesomechanics. 5(19), 104 (2016). (in Russian) [О.О. Столярова, Т.И. Муравьева, Д. Л. Загорский, Н.А. Белов. Физическая мезомеханика. 5(19), 104 (2016).]

19. N.A. Belov i dr. Aluminievye splavy antifrikcionnogo naznacheniya: A45 monogr. Moscow, MISiS (2016) 222 p. (in Russian) [Н.А. Белов и др. Алюминиевые сплавы антифрикционного назначения: A45 моногр. Москва, МИСиС (2016) 222 с.] 